VNU Journal of Science: Natural Sciences and Technology, Vol. 37, No. 1 (2021) 68-75

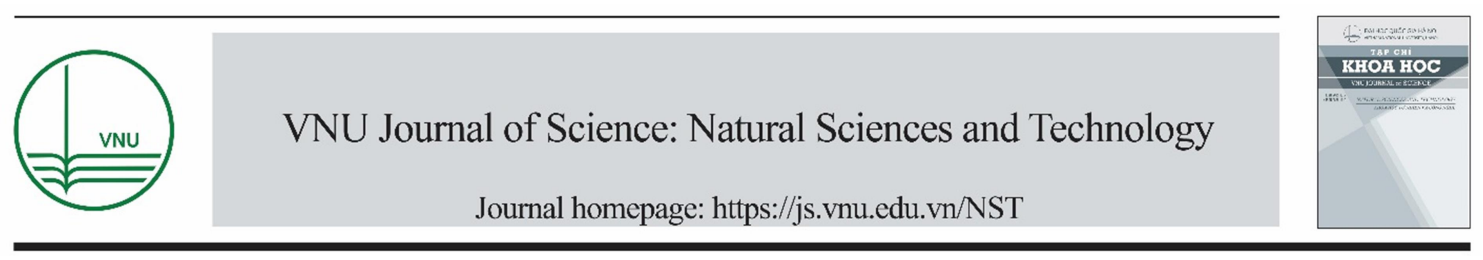

Original Article

\title{
The Diversity of Famlily Lauraceae Juss. in Pu Mat National Park, Nghe An Province
}

\author{
Do Ngoc Dai ${ }^{1, *}$, Le Thi Huong ${ }^{2}$, Dao Thi Minh Chau ${ }^{2}$, Nguyen Tien Cuong ${ }^{2}$, \\ Nguyen Cong Truong ${ }^{1}$, Le Thi Hong ${ }^{3}$ \\ ${ }^{1}$ Nghe An College of Economics, 51 Ly Tu Trong, Vinh, Vietnam \\ ${ }^{2}$ Vinh University, 182 Le Duan, Vinh, Vietnam \\ ${ }^{3}$ Hong Duc University, 332 Quang Trung, Thanh Hoa, Vietnam
}

Received 19 March 2019

Revised 11 July 2019; Accepted 06 February 2020

\begin{abstract}
This paper presents some results of research on family Lauraceae in Pu Mat National Park, Nghe An province, from 2015 to 2017. Total 90 species belonging to 13 genus of Lauraceae family were collected and identified. There were1 genera and 22 species found as new records for the plant list of $\mathrm{Pu}$ Mat published in 2017. Cinnamomum was the richest genus (26 species), then followed by Litsea (24 species), Lindera ( 8 species), and other genera (1 to 6 species). In Lauraceae of Pu Mat National Park there are 4 threatened species listed in the Red Data Book of Viet Nam (2007) are Cinnamomum parthenoxylon, Actinodaphne elliptibacca, Cinnamomum balansae, Cinnamomum cambodianum. The number of useful plant species of the Lauraceae is categorized as follows: 60 species for timber, 50 species supply essential oil, 34 species as medicinal plants, 13 species for ornamental, 3 species for edible and ornamental. The Spectrum of Biology (SB) of the Lauraceae in $\mathrm{Pu}$ Mat is summarized, as follows: $\mathrm{Ph} \%=11.11 \% \mathrm{Mg}+$ $50.00 \% \mathrm{Me}+36.67 \% \mathrm{Mi}+1.11 \% \mathrm{Na}+1.11 \mathrm{Pp}$. The Lauraceae in Pu Mat National park are mainly comprised of the tropical element $(37.78 \%)$, endemic element $(57.78 \%)$, temperate element $(2.22 \%)$ and crops element $(2.22 \%)$.
\end{abstract}

Keywords: Diversity, Lauraceae, National Park, Nghe An, Pu Mat.

\footnotetext{
* Corresponding author.

Email address: daidn23@gmail.com

https://doi.org/10.25073/2588-1140/vnunst.4877
} 


\title{
Đa dạng họ Long não (Lauraceae Juss.) ở Vườn Quốc gia Pù Mát, Nghệ An
}

\author{
Đỗ Ngọc Đài ${ }^{1, *}$, Lê Thị Hương ${ }^{2}$, Đào Thị Minh Châu ${ }^{2}$, Nguyễn Tiến Cường ${ }^{2}$, \\ Nguyễn Công Trường ${ }^{1}$, Lê Thị Hồng ${ }^{3}$
}

${ }^{I}$ Truờng Đại học Kinh tế Nghệ An, 51 Lý Tụ Trọng, Hà Huy Tập, Tp Vinh, Nghệ An, Việt Nam

${ }^{2}$ Truờng Đai học Vinh, 182 Lê Duẩn, Tp Vinh, Nghệ An, Việt Nam

${ }^{3}$ Truờng Đại học Hồng Đức, 332 Quang Trung, TP Thanh Hóa, Thanh Hóa, Việt Nam

Nhận ngày 19 tháng 3 năm 2019

Chỉnh sửa ngày 11 tháng 7 năm 2019; Chấp nhận đăng ngày 06 tháng 02 năm 2020

\begin{abstract}
Tóm tắt: Kết quả nghiên cứu họ Long não (Lauraceae) ở Vườn Quốc gia (VQG) Pù Mát, tỉnh Nghệ An, đã xác định được 90 loài, 13 chi, trong đó 1 chi và 22 loài bổ sung cho danh lục Pù Mát (2017). Các chi đa dạng nhất tại khu vực nghiên cứu là Cinnamomum-26 loài, Litsea - 24 loài, Lindera-8 loài. Có 4 loài được ghi trong Sách Đỏ Việt Nam (2007): Bộp quả bầu dục (Actinodaphne elliptibacca Kosterm.), Vù Hương (Cinnamomum balansa Lecomte), Re cam bốt (Cinnamomum cambodianum Lecomte) và Re hương (Cinnamomum parthenoxylon (Jack.) Meisn.). Các loài cây họ Long não ở khu vực nghiên cứu có các giá trị sử dụng khác nhau như cho gỗ với 60 loài, cho cho tinh dầu với 50 loài, làm thuốc với 34 loài, cho dầu béo với 13 loài, ăn được và làm cảnh với 3 loài. Lập phổ dạng sống của cây chồi trên $(\mathrm{Ph})$ của họ Long não là $\mathrm{Ph} \%=$ $11,11 \% \mathrm{Mg}+50,00 \% \mathrm{Me}+36,67 \% \mathrm{Mi}+1,11 \% \mathrm{Na}+1,11 \mathrm{Pp}$. Họ Long não ở khu vực nghiên cứu có 4 yếu tố địa lý, yếu tố nhiệt đới chiếm $37,78 \%$, yếu tố đặc hữu chiếm $57,78 \%$; yếu tố ôn đới và yếu tố cây trồng cùng chiếm $2,22 \%$.
\end{abstract}

Từ khóa: Đa dạng, Họ Long não, Pù Mát, Vườn Quốc gia, Nghệ An.

\section{Mở đầu}

Trên thế giới, họ Long não (Lauraceae) có khoảng 52 chi với gần 3.500 loài, phân bố chủ yếu ở vùng nhiệt đới và cận nhiệt đới [1]. Việt Nam là nước nằm trong khu vực nhiệt đới gió mùa, do đó có nguồn tài nguyên thiên nhiên tương đối đa dạng, trong đó các loài trong họ Long não cũng sinh trưởng và phát triển mạnh. Hiện nay, theo điều tra của các nhà khoa học, thì ở Việt Nam có khoảng $21 \mathrm{chi}, 280$ loài và thứ [2]. Đây là họ có tính đa dạng và có ý nghĩa

\footnotetext{
*Tác giả liên hệ.

Địa chỉemail: daidn23@gmail.com

https://doi.org/10.25073/2588-1140/vnunst.4877
}

trong đời sống con người như sử dụng làm thuốc, làm thực phẩm, cho tinh dầu [3]

VQG Pù Mát có vị trí $18^{0} 46^{\prime} 30^{\prime \prime}-19^{0} 19^{\prime} 42^{\prime \prime}$ vĩ độ Bắc và $104^{0} 31^{\prime} 54^{\prime \prime}-105^{\circ} 08^{\prime} 03^{\prime \prime}$ độ Kinh đông, nằm phía Tây - Nam tỉnh Nghệ An với diện tích vùng lõi 94.408 ha và vùng đệm 86.000 ha. Hiện nay, đã có nhiều công trình nghiên cứu về hệ thực vật ở đây như Nguyễn Nghĩa Thìn và Nguyễn Thanh Nhàn [4], Đào thị Minh Châu [5], Nguyễn Viết Hùng [6], Nguyễn Thanh Nhàn [7]. Tuy nhiên, các tác giả chỉ đề cập đến những khía cạnh khác nhau về thực vật, chưa đánh giá thống kê đầy đủ về các taxon bậc họ. Bài báo này cung cấp thêm những dẫn liệu về tính đa dạng chi và loài họ Long não ở VQG Pù Mát để góp phần phát hiện, thống kê đầy đủ về 
các taxon bậc họ giúp cho công tác bảo tồn tài nguyên thiên nhiên một cách hợp lý.

\section{Vật liệu và phương pháp nghiên cứu}

Đối tượng nghiên cứu là các loài họ Long não (Lauraceae Juss.) phân bố ở VQG Pù Mát, Nghệ An.

Mẫu vật được thu thập theo phương pháp nghiên cứu của Nguyễn Nghĩa Thìn [8], thời gian thực hiện từ tháng 08/2015 đến 09/2017. Tổng số mẫu thu được là 302 mẫu tiêu bản và được lưu trữ tại Bộ môn Lâm nghiệp, Trường Đại học Kinh tế Nghệ An.

Định loại: Sử dụng phương pháp hình thái so sánh theo các tài liệu của Phạm Hoàng Hộ [8], Nguyễn Kim Đào [2], Thực vật chí Trung Quốc [1].

Đánh giá về giá trị sử dụng dựa vào phương pháp phỏng vấn có sự tham gia (PRA) và dựa vào các tài liệu của Võ Văn Chi [3], Trần Đình
Lý và cộng sự [9], Đỗ Tất Lợi [10], Đỗ Huy Bích và cộng sự [11], Triệu Văn Hùng và cộng sự [12]. Đánh giá yếu tố địa lý theo Nguyễn Nghĩa Thìn [13]. Đánh giá về dạng sống theo Raunkiaer) [14]. Đánh giá về các loài nguy cấp theo Sách Đỏ Việt Nam [15], IUCN [16] và NDD32/CP [17].

\section{Kết quả và thảo luận}

\section{1. Đa dạng về thành phần loài}

Qua điều tra, thu thập mẫu thực vật, định danh về các loài thuộc họ Long não (Lauraceae) ở Vườn Quốc gia Pù Mát, Nghệ An. Bước đầu đã xác định được 90 loài, 13 chi; so với công trình của Nguyễn Viết Hùng [6], Nguyễn Thanh Nhàn (2017) [7] đã ghi nhận mới cho VQG Pù Mát 01 chi và 22 loài (Bảng 1 ).

Bảng 1. Danh lục thực vật họ Long não (Lauraceae) ở Vườn Quốc gia Pù Mát, Nghệ An

\begin{tabular}{|c|c|c|c|c|c|}
\hline $\mathrm{TT}$ & Tên khoa học & Tên Việt Nam & $\begin{array}{l}\text { Yếu tố } \\
\text { địa lý }\end{array}$ & $\begin{array}{l}\text { Dạng } \\
\text { sông }\end{array}$ & $\begin{array}{l}\text { Giá trị } \\
\text { sử dụng }\end{array}$ \\
\hline 1 & Actinodaphne ellipticibacca Kosterm. & Bộp quả bầu dục & 6 & $\mathrm{Me}$ & $\mathrm{T}$ \\
\hline 2 & Actinodaphne obovata (Nees) Blume & Bộp xoan ngược & 4.4 & $\mathrm{Mi}$ & $\mathrm{T}$ \\
\hline 3 & Actinodaphne pilosa (Lour.) Merr. & Bộp lông & 6.1 & $\mathrm{Mi}$ & $\mathrm{M}, \mathrm{E}$ \\
\hline 4 & Alseodaphne tonkinensis Liou & Sụ bắc & 6 & $\mathrm{Me}$ & $\mathrm{E}, \mathrm{T}$ \\
\hline 5 & Beilschmiedia ferruginea Liou & Chắp két & 6 & $\mathrm{Me}$ & $\mathrm{T}$ \\
\hline 6 & Beilschmiedia laotica Kosterm. & Chắp lào & 6.1 & $\mathrm{Me}$ & $\mathrm{T}$ \\
\hline 7 & Beilschmiedia percoriacea Allen & Chắp dai & 6.1 & $\mathrm{Me}$ & $\mathrm{T}$ \\
\hline 8 & Beilschmiedia sphaerocarpa Lecomte & Chắp quả hình cầu & 6 & $\mathrm{Me}$ & $\mathrm{T}$ \\
\hline 9 & Beilschmiedia tsangii Merr. & Chắp tsang & 6.1 & $\mathrm{Mi}$ & $\mathrm{T}$ \\
\hline 10 & Cassytha filiformis L. & Tơ xanh & 4.4 & $\mathrm{Pp}$ & M,E \\
\hline 11 & Cinnamomum auricolor Kosterm. & Re tía & 6 & $\mathrm{Me}$ & $\mathrm{E}, \mathrm{T}$ \\
\hline 12 & Cinnamomum balansae Lecomte & Vù hương & 6 & $\mathrm{Mg}$ & M,E,T \\
\hline 13 & Cinnamomum bonii Lecomte & Quế bon & 6.1 & $\mathrm{Me}$ & M,E,T,Oil \\
\hline 14 & $\begin{array}{l}\text { Cinnamomum burmanii (C.\& } \text { T. Nees.) } \\
\text { Blume }\end{array}$ & Trèn trèn trắng & 4 & $\mathrm{Mg}$ & $\mathrm{M}, \mathrm{E}, \mathrm{T}$ \\
\hline 15 & Cinnamomum cambodianum Lecomte & Re cam bốt & 6.1 & $\mathrm{Me}$ & M,E,T \\
\hline 16 & Cinnamomum camphora (L.) Persl & Long não & 5.4 & $\mathrm{Me}$ & M,E,T \\
\hline 17 & Cinnamomum caryophyllus (Lour.) Moore & Re cẩm chướng & 6 & $\mathrm{Me}$ & M,E,T \\
\hline 18 & Cinnamomum cassia Presl & Quế thanh & 4 & $\mathrm{Me}$ & M,E,T \\
\hline 19 & Cinnamomum glaucescens (Nees) Drury & Re xanh phấn & 4.2 & $\mathrm{Me}$ & $\mathrm{E}, \mathrm{T}$ \\
\hline
\end{tabular}




\begin{tabular}{|c|c|c|c|c|c|}
\hline 20 & Cinnamomum impressineurium Meissn. & Re gân lõm & 6 & $\mathrm{Mi}$ & $E$ \\
\hline 21 & Cinnamomum iners Reinw. ex Blume & Quế lợn & 4 & $\mathrm{Mi}$ & M,E,T \\
\hline 22 & Cinnamomum kunstleri Rindl. & Quế kunstler & 4.1 & $\mathrm{Me}$ & $\mathrm{E}, \mathrm{T}$ \\
\hline 23 & Cinnamomum longipes (Jonhst.) Kosterm. & Re cọng dài & 7 & Mi & $\mathrm{E}$ \\
\hline 24 & Cinnamomum loureirii Nees & Nhục quế & 4.4 & $\mathrm{Me}$ & M,E,T \\
\hline 25 & Cinnamomum mairei Levl. & Quế bạc & 6.1 & $\mathrm{Me}$ & $\mathrm{M}, \mathrm{E}$ \\
\hline 26 & Cinnamomum melastomaceum Kosterm. & Re muôi & 6 & $\mathrm{Me}$ & $\mathrm{E}, \mathrm{T}$ \\
\hline 27 & Cinnamomum ovatum Allen & Re trứng & 6.1 & $\mathrm{Me}$ & M,E,T \\
\hline 28 & Cinnamomum parthnoxylon (Jack) Meisn. & Vù hương & 6.1 & $\mathrm{Mg}$ & M,E,T,Oil \\
\hline 29 & Cinnamomum polyadelphum (Lour.) Kosterm. & Quế bời lời & 4.2 & $\mathrm{Mg}$ & T,Ed \\
\hline 30 & Cinnamomum rigidifolium Kosterm. & Quế lá cứng & 6 & $\mathrm{Mi}$ & $\mathrm{E}$ \\
\hline 31 & Cinnamomum scortechinii Gamble & Re scortechin & 4.1 & $\mathrm{Me}$ & $\mathrm{E}, \mathrm{T}$ \\
\hline 32 & Cinnamomum subpennivervium Kosterm. & Re lông chim & 6 & $\mathrm{Me}$ & $\mathrm{T}$ \\
\hline 33 & $\begin{array}{l}\text { Cinnamomum tamala (Buch.-Ham.) Nees et } \\
\text { Eberm }\end{array}$ & Re chay & 4.2 & $\mathrm{Me}$ & M,E,T \\
\hline 34 & Cinnamomum tetragonum A. Chev. & Quế đỏ & 6.1 & Me & $\mathrm{M}, \mathrm{E}, \mathrm{T}$ \\
\hline 35 & Cinnamomum tonkinensis (Lecomte) A. Chev. & Re xanh & 6.1 & $\mathrm{Me}$ & $\mathrm{E}, \mathrm{T}$ \\
\hline 36 & Cryptocarya chinensis (Hance) Hemsl. & Cà đuối trung quốc & 6.1 & $\mathrm{Me}$ & $\mathrm{T}$ \\
\hline 37 & Cryptocarya chingii Cheng & Mò hương & 6.1 & $\mathrm{Me}$ & $\mathrm{T}$ \\
\hline 38 & Cryptocarya concinna Hance & Mò quả vàng & 6.1 & $\mathrm{Mg}$ & $\mathrm{T}$ \\
\hline 39 & Cryptocarya ferrea Blume & Ẩn hạt sét & 4.1 & $\mathrm{Mg}$ & $\mathrm{T}$ \\
\hline 40 & Cryptocarya infectoria (Blume) Miq. & Cà đuối nhuộm & 4.1 & $\mathrm{Me}$ & $\mathrm{T}$ \\
\hline 41 & Cryptocarya maclurei Merr. & Mò lá bạc & 4.1 & $\mathrm{Me}$ & $\mathrm{T}$ \\
\hline 42 & $\begin{array}{l}\text { Endiandra hainanensis Merr. \& Metc. ex } \\
\text { Allen }\end{array}$ & Khuyết nhị hải nam & 6.1 & $\mathrm{Me}$ & Or,T \\
\hline 43 & Lindera caudata (Nees) Hook. f. & Ô đước đuôi & 4.2 & Mi & E,T,Oil \\
\hline 44 & Lindera chunii Merr. & Ô đước chun & 6.1 & Mi & M,T \\
\hline 45 & Lindera communis Hemsl. & Ô đước thường & 6.1 & $\mathrm{Mi}$ & M,E,T,Oil \\
\hline 46 & Lindera glauca (Sieb. et Zucc.) Blume & Ô đước mốc & 6.1 & Mi & M,E,Oil \\
\hline 47 & Lindera myrrha (Lour.) Merr. & Dầu đắng & 6 & Mi & $\mathrm{M}, \mathrm{E}$ \\
\hline 48 & Lindera nacusua (D. Don) Merr. & Ô đước đôi & 6.1 & $\mathrm{Me}$ & $\mathrm{T}$ \\
\hline 49 & Lindera racemosa Lecomte & Lòng trứng hoa vàng & 6 & $\mathrm{Me}$ & \\
\hline 50 & Lindera tonkinensis Lecomte & Ô đước bắc & 6.1 & $\mathrm{Mi}$ & M,E,T \\
\hline 51 & Litsea balansa Lecomte & Bời lời balansa & 6.1 & $\mathrm{Mi}$ & $\mathrm{E}$ \\
\hline 52 & Litsea baviensis Lecomte & Bời lời ba vì & 6.1 & $\mathrm{Me}$ & E,T \\
\hline 53 & Litsea cambodiana Lecomte & Bời lời cam bốt & 6.1 & $\mathrm{Mg}$ & M,T,Oil \\
\hline 54 & Litsea chartacea (Wall. ex Nees.) Hook. & Bời lời da & 4.2 & Mi & $\mathrm{E}$ \\
\hline 55 & Litsea clememsii Allen & Bời lời clemen & 6 & $\mathrm{Mi}$ & $\mathrm{E}$ \\
\hline 56 & Litsea cubeba (Lour.) Pers & Màng tang & 6 & $\mathrm{Mi}$ & M,E,T \\
\hline 57 & Litsea elongata (Ness) Hook.f. & Bời lời lá thuôn & 4.2 & $\mathrm{Me}$ & $\mathrm{E}$ \\
\hline 58 & Litsea eugenoides A. Chev. & Bời lời tram & 6 & Mi & $\mathrm{E}$ \\
\hline 59 & Litsea euosma W.W. Smith & Bời lời núi đá & 6.1 & $\mathrm{Me}$ & M,E,Oil \\
\hline 60 & Litsea ferruginea Liou & Bời lời gỉ sắt & 6 & Mi & $\mathrm{E}$ \\
\hline 61 & Litsea glutinosa (Lour.) C. B. Robins & Bời lớt nhớt & 4 & $\mathrm{Me}$ & $\mathrm{M}, \mathrm{E}, \mathrm{T}$ \\
\hline 62 & Litsea griffithii Gamble & Bời lời trung bộ & 6 & Mi & $\mathrm{T}$ \\
\hline
\end{tabular}




\begin{tabular}{|c|c|c|c|c|c|}
\hline 63 & Litsea helferi Hook. f. & Bời lời xám liệm & 4.2 & $\mathrm{Mi}$ & \\
\hline 64 & Litsea lancifolia (Roxb. \& Nees) Hook. f. & Bời lời lá mác & 4 & Mi & M \\
\hline 65 & Litsea mollifolia Chun & Bời lời lá mềm & 6.1 & $\mathrm{Mi}$ & E,Oil \\
\hline 66 & Litsea monopetala (Roxb.) Pers & Bời bời lá tròn & 4.4 & $\mathrm{Me}$ & M,T,E \\
\hline 67 & Litsea myristicaefolia (Meisn.) Hook.f. & Bời lời nhục đậu khấu & 4.2 & $\mathrm{Me}$ & $E$ \\
\hline 68 & Litsea robusta Blume & Bời lời mạnh & 4.1 & $\mathrm{Me}$ & $\mathrm{T}$ \\
\hline 69 & Litsea salmonea A. Chev. & Bời lời đỏ tươi & 6 & $\mathrm{Mi}$ & $\mathrm{E}$ \\
\hline 70 & Litsea umbellata (Lour.) Merr. & Bời lời đắng & 4.1 & $\mathrm{Mi}$ & M,E \\
\hline 71 & Litsea variabilis Hemsl. & Bời bời biến dị & 4.4 & $\mathrm{Mi}$ & $\mathrm{M}, \mathrm{T}$ \\
\hline 72 & Litsea verticillata Hance & Bời bời lá vòng & 4.4 & $\mathrm{Mi}$ & $\mathrm{E}, \mathrm{T}$ \\
\hline 73 & Litsea viridis H. Liu & Bời lời lục & 6.1 & $\mathrm{Mi}$ & \\
\hline 74 & Litsea yunnanensis Yang et P. H. Hoang & Bời lời vân nam & 6.1 & $\mathrm{Me}$ & $\mathrm{T}$ \\
\hline 75 & Machilus leptophylla Hand.-Mazz. & Kháo nhớt & 6.1 & $\mathrm{Me}$ & $\mathrm{T}$ \\
\hline 76 & Machilus odoratissima Nees & Kháo nhậm & 4 & $\mathrm{Mg}$ & $\mathrm{E}, \mathrm{T}$ \\
\hline 77 & Machilus platicarpa Chun & Kháo lá dẹt & 6.1 & $\mathrm{Mg}$ & $\mathrm{M}, \mathrm{T}$ \\
\hline 78 & Machilus thunberghii Sieb. et Zucc. & Kháo vàng bông & 5.4 & $\mathrm{Me}$ & M,E,T,Oil \\
\hline 79 & Machilus velutina Champ. ex Benth. & Kháo lông nhung & 6.1 & $\mathrm{Me}$ & M,Oil \\
\hline 80 & Neolitsea angustifolia A. Chev. & Nô lá hẹp & 6 & Mi & \\
\hline 81 & Neolitsea buisanensis Yam et Kam. & Nô bùi san & 4.5 & $\mathrm{Mi}$ & \\
\hline 82 & Neolitsea poilanei Liou & Nô poilan & 6 & $\mathrm{Me}$ & $\mathrm{T}$ \\
\hline 83 & Neolitsea zeylanica (C. \& T. Nees) Merr. & Nô zeylan & 4.2 & $\mathrm{Me}$ & $\mathrm{M}, \mathrm{T}$ \\
\hline 84 & Persea americana Mill. & Bơ & 7 & $\mathrm{Mi}$ & Ed,Oil \\
\hline 85 & Phoebe angustifolia Meisn. & Re trắng lá hẹp & 4.2 & $\mathrm{Na}$ & $\mathrm{E}$ \\
\hline 86 & Phoebe cuneata Blume & Re trắng hình nêm & 4.1 & $\mathrm{Mi}$ & $\mathrm{E}$ \\
\hline 87 & Phoebe lanceolata (Wall. ex Nees) Nees & Re trắng mũi mác & 4 & $\mathrm{Me}$ & M,E,T \\
\hline 88 & Phoebe macrocarpa C. Y. Wu & Re trắng quả to & 6.1 & $\mathrm{Mg}$ & $\mathrm{T}$ \\
\hline 89 & Phoebe paniculata Nees. & Re trắng chùy & 4.2 & $\mathrm{Mi}$ & $\mathrm{E}$ \\
\hline 90 & Phoebe tavoyana (Meissn.) Hook. f. & Re trắng lá to & 4.2 & $\mathrm{Me}$ & M,T \\
\hline
\end{tabular}

Ghi chú: * loài bổ sung cho VQG Pù Mát; 4. Châu Á; 4.3. Lục địa châu Á nhiệt đới;4.4. Đông Dương - Nam Trung Quốc; 4.5. Đông Dương; 6.1. Gần đặc hữu; 6.2. Đặc hữu Việt Nam; 7. Cây trồng; 8. Yếu tố chưa xác định; M: Làm thuốc; T: Cho gỗ; E: Cho tinh dầu; Oil: Cho dầu béo; Ed: Ăn được; Or: Làm cảnh; Mg: cây chồi trên rất lớn; Me: Cây chồi trên lớn; Mi; cây chồi trên nhỡ; Na: cây chồi trên nhỏ; Pp: cây ký sinh, bán ký sinh.

Bảng 2. Phân bố các loài trong các chi của họ Long não ở VQG Pù Mát

\begin{tabular}{|c|c|c|c|c|c|c|}
\hline \multirow{2}{*}{ TT } & \multirow{2}{*}{ Tên chi } & \multirow{2}{*}{ Số loài } & \multicolumn{4}{|c|}{ Số chi có } \\
\hline & & & 1 loài & 2 loài & 3 loài & trên 4 loài \\
\hline 1 & Actinodaphne & 3 & & & $\mathrm{X}$ & \\
\hline 2 & Alseodaphne & 1 & $\mathrm{x}$ & & & \\
\hline 3 & Beilschmiedia & 5 & & & & $\mathrm{x}$ \\
\hline 4 & Cassytha & 1 & $\mathrm{x}$ & & & \\
\hline 5 & Cinnamomum & 25 & & & & $x$ \\
\hline 6 & Cryptocarya & 6 & & & & $\mathrm{x}$ \\
\hline 7 & Endiandra & 1 & $\mathrm{x}$ & & & \\
\hline 8 & Lindera & 8 & & & & $\mathrm{x}$ \\
\hline 9 & Litsea & 24 & & & & $\mathrm{x}$ \\
\hline 10 & Machilus & 5 & & & & $\mathrm{x}$ \\
\hline
\end{tabular}




\begin{tabular}{llccc}
\hline 11 & Neolitsea & 4 & & $\mathrm{x}$ \\
\hline 12 & Persea & 1 & $\mathrm{x}$ & $\mathrm{x}$ \\
\hline 13 & Phoebe & 6 & & \\
\hline & Tổng & 90 & & \\
\hline
\end{tabular}

\subsection{Số lượng loài trong các chi}

Kết quả nghiên cứu đã thống kê được 13 chi của họ Long não (Lauraceae) phân bố ở Vườn Quốc gia Pù Mát, trong đó số lượng loài gặp trong mỗi chi là khác nhau, được thể hiện qua Bảng 2.

Kết quả Bảng 2 cho thấy, chi Cinnamomum là đa dạng nhất tại khu vực nghiên cứu với 25 loài (chiếm $35,42 \%$ tổng số loài), chi Litsea có 24 loài (chiếm 18,75\%); chi Linderacó 8 loài (16,67\%), các chi Crryptocaya, Phoebe có 6 loài (chiếm 8,33\%), các chi còn lại có từ 1 đến 5 loài.

\section{3. Đa dạng về giá trị sử dụng}

Giá trị sử dụng dựa theo các tài liệu của Võ Văn Chi [3], Nguyễn Kim Đào [2], Trần Đình Lý và cộng sự [10], Đỗ Tất Lợi [11],... Kết quả được trình bày ở Bảng 3 .

Trong đó, cây cho gỗ với 60 loài chiếm $66,67 \%$ tổng số loài; cây cho tinh dầu với 50 loài chiếm $55,56 \%$; cây làm thuốc với 34 loài chiếm $37,38 \%$; cây cho dầu béo với 13 loài chiếm $14,44 \%$, cây ăn được và cây làm cảnh với 3 loài chiếm $3,33 \%$. Như vậy, trong các nhóm giá trị sử dụng thì nhóm cây cho gỗ với số lượng loài nhiều nhất, điều này cũng hoàn toàn hợp lý bởi vì đây là một họ thực vật chiếm ưu thế ở vùng nhiệt đới và ôn đới, có nhiều loài cây tham gia cấu thảnh tổ hợp thực vật.

Bảng 3. Giá trị sử dụng của họ Long não (Lauraceae) ở VQG Pù Mát

\begin{tabular}{clcc}
\hline TT & Giá trị sử dụng & $\begin{array}{c}\text { Số } \\
\text { lượng }\end{array}$ & Tỷ lệ \% \\
\hline 1 & Cây lấy gố & 60 & 66,67 \\
\hline 2 & Cây cho tinh dầu & 50 & 55,56 \\
\hline 3 & Cây làm thuốc & 34 & 37,78 \\
\hline 4 & Cây cho dầu béo & 13 & 14,44 \\
\hline 5 & $\begin{array}{l}\text { Cây ăn được và làm } \\
\text { cảnh }\end{array}$ & 3 & 3,33 \\
\hline
\end{tabular}

*Một loài có thể cho 1 hoặc nhiều giá trị sử dụng khác nhau

\section{4. Đa dạng về dạng sống}

Áp dụng hệ thống phân loại dạng sống của Raunkiear [14] cho họ Long não (Lauraceae) ở VQG Pù Mát, trong số 90 loài và thứ được xác định thì nhóm dạng sống chồi trên chiếm ưu thế tuyệt đối với tỉ lệ $100 \%$, không có các nhóm dạng sống khác. Trong nhóm cây chồi trên thì các nhóm phụ phân bố không đều nhau (Bảng 4).

Bảng 4. Tỉ lệ của các dạng sống nhóm cây chồi trên $(\mathrm{Ph})$

\begin{tabular}{ccccccc}
\hline Dạng sống & $\mathrm{Mg}$ & $\mathrm{Me}$ & $\mathrm{Mi}$ & $\mathrm{Na}$ & $\mathrm{Pp}$ & Tổng \\
\hline Số loài & 10 & 45 & 33 & 1 & 1 & 90 \\
\hline Tỷ lệ \% & 11,11 & 50,00 & 36,67 & 1,11 & 1,11 & 100 \\
\hline
\end{tabular}

Từ kết quả thu được ở Bảng 4, đã lập phổ dạng sống cho nhóm cây chồi trên $(\mathrm{Ph})$ của họ Long não ở VQG Pù Mát như sau:

$$
\begin{gathered}
\mathrm{Ph} \%=11,11 \% \mathrm{Mg}+50,00 \% \mathrm{Me}+36,67 \% \mathrm{Mi}+ \\
1,11 \% \mathrm{Na}+1,11 \mathrm{Pp} .
\end{gathered}
$$

Như vậy, nhóm dạng sống cây chồi trên vừa (Mi) và lớn $(\mathrm{Me})$ chiếm ưu thế với $35,06 \%$ và $33,77 \%$ tổng số loài, điều này cũng hợp lý với tính đặc trưng của các loài trong họ Long não, chúng chủ yếu thuộc các chi Litsea, Cinnamomum, Actinodaphne. Nhóm cây chồi nhỏ, cây chồi rất lớn và cây chồi ký sinh chiếm tỷ lệ không đáng kể.

\section{5. Đa dạng về yếu tố địa lý}

Từ bảng danh lục thực vật, đã thống kê yếu tố địa lý của các loài thuộc họ Long não (Lauraceae) ở VQG Pù Mát, Nghệ An (Bảng 5).

Bảng 5. Yếu tố địa lý của các loài trong họ Long não ở VQG Pù Mát 


\begin{tabular}{|c|c|c|c|c|c|}
\hline $\begin{array}{l}\text { Ký } \\
\text { hiệu }\end{array}$ & Các yếu tố địa lý & Số loài & $\begin{array}{l}\text { Tỷ lệ } \\
\text { (\%) }\end{array}$ & Số loài & $\begin{array}{l}\text { Tỷ lệ } \\
(\%)\end{array}$ \\
\hline 1 & Toàn thế giới & 0 & 0 & 0 & 0 \\
\hline 2 & Liên nhiệt đới & 0 & 0 & \multirow{2}{*}{$\begin{array}{l}\text { Liên nhiệt } \\
\text { đới }\end{array}$} & \multirow{4}{*}{0} \\
\hline 2.1 & Nhiệt đới châu Á, châu Úc, châu Mĩ & 0 & 0 & & \\
\hline 2.2 & Nhiệt đới châu Á, châu Phi và Châu Mỹ & 0 & 0 & \multirow{2}{*}{0} & \\
\hline 2.3 & Nhiệt đới châu Á và Châu Mỹ & 0 & 0 & & \\
\hline 3 & Cổ nhiệt đới & 0 & 0 & \multirow{2}{*}{ Cổ nhiệt đới } & \multirow{3}{*}{0} \\
\hline 3.1 & Nhiệt đới châu Á và châu Úc & 0 & 0 & & \\
\hline 3.2 & Nhiệt đới châu Á và châu Phi. & 0 & 0 & 0 & \\
\hline 4 & Nhiệt đới châu Á & 7 & 7,78 & \multirow{3}{*}{$\begin{array}{l}\text { Nhiệt đới } \\
\text { châu Á }\end{array}$} & \multirow{6}{*}{37,78} \\
\hline 4.1 & Đông Dương - Malêzi & 8 & 8,89 & & \\
\hline 4.2 & Lục địa châu Á nhiệt đới & 12 & 13,33 & & \\
\hline 4.3 & Lục địa Đông Nam Á & 0 & 0,00 & \multirow{3}{*}{34} & \\
\hline 4.4 & Đông Dương - Nam Trung Quốc & 6 & 6,67 & & \\
\hline 4.5 & Đông Dương & 1 & 1,11 & & \\
\hline 5 & Ôn đới Bắc & 0 & 0 & \multirow{3}{*}{ Ôn đới } & \multirow{5}{*}{2,22} \\
\hline 5.1 & Đông Á-Bắc Mỹ & 0 & 0 & & \\
\hline 5.2 & Ôn đới cổ thế giới & 0 & 0 & & \\
\hline 5.3 & Ôn đới Địa Trung Hải-Châu Âu-Châu Á & 0 & 0 & \multirow{2}{*}{2} & \\
\hline 5.4 & Đông Á & 2 & 2,22 & & \\
\hline 6 & Đặc hữu Việt Nam & 21 & 23,33 & Đặc hữu & \multirow{2}{*}{57,78} \\
\hline 6.1 & Cận đặc hữu Việt Nam & 31 & 34,44 & 52 & \\
\hline \multirow[t]{2}{*}{7} & Cây trồng & 2 & 2,22 & 2 & 2,22 \\
\hline & Tổng & 90 & 100 & 90 & 100 \\
\hline
\end{tabular}

Kết quả nghiên cứu phân bố yếu tố địa lý 90 loài và thứ của họ Long não ở khu vực nghiên cứu. Trong đó, yếu tố nhiệt đới với 7 loài chiếm $7,78 \%$, tiếp đến là yếu tố đặc hữu với 10 loài chiếm 23,81\%; yếu tố Đông Dương - Nam Trung Quốc với 12 loài chiếm $28,57 \%$; yếu tố Đông Dương với 7 loài chiếm $16,67 \%$; yếu tố chưa xác định với 3 loài chiếm $7,14 \%$ và thấp nhất là yếu tố cây trồng với 2 loài chiếm $4,76 \%$. Kết quả nghiên cứu này là hợp lí bởi các loài cây họ Long não là những cây nhiệt đới và cận nhiệt đới, chúng phân bố ở những nơi có nhiệt độ tương đối cao, còn những khu vực có nhiệt độ thấp thì chúng sinh trưởng và phát triển kém hơn. Ngoài ra yếu tố đặc hữu và Đông Dương chiếm tỷ lệ khá cao, điều đó chứng minh cho tính độc đáo của họ Long não ở khu vực nghiên cứu nói riêng và Việt Nam nói chung.

3.6. Đa dạng về nguồn gen quý hiếm
Kết quả nghiên cứu đã xác định được 04 loài ở mức rất nguy cấp $(\mathrm{CR})$ và sẽ nguy cấp (VU) trong Sách Đỏ Việt Nam 2007 [15]. Trong đó, có 1 loài rất nguy cấp $(\mathrm{CR})$ là $\mathrm{Re}$ hương (Cinnamomum parthenoxylon (Jack.) Meisn.). Các loài Bộp quả bầu dục (Actinodaphne elliptibacca Kosterm.), Vù hương (Cinnamomum balansae Lecomte), Re cam bốt (Cinnamomum cambodianum Lecomte) ở mức độ nguy cấp (VU). Loài Vù hương (Cinnamomum balansae Lecomte) thuộc danh lục đỏ thế giới (IUCN, 2017) [16] ở mức nguy cấp (EN) và NĐ32/CP (2006) [17] cấm khai thác và buôn bán với mục đích thương mại. Đây là những loài có giá trị kinh tế như cho tinh dầu, làm thuốc đặc biệt gỗ rất tốt nên bị khai thác triệt để, hiện nay chỉ còn lại những cây gỗ nhỏ tái sinh. Do vậy cần có những chính sách phù hợp để phục hồi và bảo tồn chúng.

\section{Kết luận}


Kết quả nghiên cứu họ Long não ở VQG Pù Mát đã xác định được 90 loài, 13 chi, bồ sung vào danh lục Pù Mát (2017) là 01 chi và 22 loài.

Các chi đa dạng nhất của họ Long não (Lauraceae) là Cinnamomum, Litsea, Lindera, Cryptocaya, Phoebe.

Họ Long não ở Pù Mát có nhiều loài cây có giá trị sử dụng, cây cho gỗ với 60 loài, cây cho tinh dầu với 50 loài, cây làm thuốc với 34 loài, cây cho dầu béo với 13 loài, cây làm cảnh và ăn được với 3 loài.

Dạng sống của các loài trong họ Long não ở khu vực nghiên cứu chỉ có nhóm cây chồi trên $(\mathrm{Ph})$ với công thức là: $\mathrm{Ph} \%=11,11 \% \mathrm{Mg}+$ $50,00 \% \mathrm{Me}+36,67 \% \mathrm{Mi}+1,11 \% \mathrm{Na}+1,11 \mathrm{Pp}$.

Trong các yếu tố địa lý thì yếu tố nhiệt đới chiếm $37,78 \%$, yếu tố đặc hữu chiếm $57,78 \%$; yếu tố ôn đới và yếu tố cây trồng cùng chiếm $2,22 \%$.

Có 4 loài được ghi trong Sách Đỏ Việt Nam (2007) là Bộp quả bầu dục (Actinodaphne elliptibacca Kosterm.), Vù Hương (Cinnamomum balansa Lecomte), Re cam bốt (Cinnamomum cambodianum Lecomte) và $\mathrm{Re}$ hương (Cinnamomum parthenoxylon (Jack.) Meisn.).

\section{Lời cảm ơn}

Nghiên cứu này được tài trợ bởi Quỹ Phát triển khoa học và công nghệ Quốc gia (NAFOSTED) trong đề tài mã số: 106.03.2018.02.

\section{Tài liệu tham khảo}

[1] K. Zhang, H.W. Li, J. Li, P.H. Huang, F. Wei, H. P. Tsui, H.V.D. Werff, Flora of China, Science Press, Beijing, and Missouri Botanical Garden Press, St. Louis, 2008.

[2] N.K. Dao, flora in Vietnam, Publishing house, Natural Science and Technology, 2017 (in Vietnamese).

[3] V.V. Chi, Dictionary Medicinal of Vietnam, Medicine Publishing house, Hanoi, 2012 (in Vietnamese).
[4] N.N. Thin, N.T. Nhan, Diversity of Plants in Pu Mat National Park, Agriculture Publishing house, Hanoi, 2004 (in Vietnamese).

[5] D.T.M. Chau, Research NTFPs in Pu Mat National Park to propose solutions to mining and development, $\mathrm{PhD}$ Thesis in Biology, Hanoi, 2016 (in Vietnamese).

[6] N.V. Hung, Research composition essential oil plants in $\mathrm{Pu}$ Mat National Park and và propose conservation solutions, $\mathrm{PhD}$ Thesis in Biology, Vinh, 2017 (in Vietnamese).

[7] N.T. Nhan, Researching plant diversity in $\mathrm{Pu}$ Mat National Park and proposing conservation solutions, PhD. In Biology, Vinh, 2017 (Vietnamese).

[8] P.H. Ho, An Instrated Flora of Vietnam, Youth Publishing house, Ho Chi Minh, 2000 (in Vietnamese).

[9] T.D. Ly, 1900 Useful species in Vietnam, World Publishing house, 1993 (in Vietnamese).

[10] D.T. Loi, Vietnamese medicinal plants and herbs, Science and Techology Publishing house, Hanoi, 2001 (in Vietnamese).

[11] D.H. Bich, D.Q. Trung, B.X. Chuong, N.T. Dong, D.T. Dam, P.V. Hien, V.N. Lo, P.D. Mai, P.K. Man, D.T. Nhu, N. Tap, T. Toan, Medicinal plants and medicinal animals in Vietnam, Science and Techology Publishing house, Hanoi, 2004 (in Vietnamese).

[12] T.V. Hung, Vietnam non-timber forest products, Map Publishing house, Ha Noi, 2007 (in Vietnamese).

[13] N.N. Thin, Plants research methods, Vietnam National University, Hanoi Publishing house, 2007 (in Vietnamese).

[14] C. Raunkiær, The Life Forms of Plants and Statistical Plant Geography, Introduction by A.G. Tansley, Oxford University Press, Oxford.

[15] Ministry of Science and Technology - Vietnam Academy of Science and Technology, Vietnam Red Book, Part II-Plant, Publihing house, Natural Science and Technology, Hanoi (in Vietnamese).

[16] The IUCN species survival Comission (2017), Red List of Threatened species TM 2017 International Union for the Conservation of Nature and Nature Resources.

[17] Government of Vietnam, Decree 32/2006/ NDCP dated March 30, 2006, List of endangered, precious and rare forest plants and animals, 2006 (in Vietnamese). 